\title{
Beyond Productivity: Considering the Health, Social Value and Happiness of Home and Community Food Gardens
}

\author{
Georgia Pollard ${ }^{1, *} \mathbb{\infty}$, Philip Roetman ${ }^{1}$, James Ward ${ }^{1}$, Belinda Chiera ${ }^{2}$ \\ and Evangeline Mantzioris ${ }^{3}$ \\ 1 School of Natural \& Built Environments, Mawson Lakes Campus, University of South Australia, \\ Adelaide, SA 5095, Australia; Philip.Roetman@unisa.edu.au (P.R.); James.Ward@unisa.edu.au (J.W.) \\ 2 School of Information Technology and Mathematical Sciences, City West Campus, \\ University of South Australia, Adelaide, SA 5000, Australia; Belinda.Chiera@unisa.edu.au \\ 3 School of Pharmacy and Medical Sciences, City East Campus, University of South Australia, \\ Adelaide, SA 5000, Australia; Evangeline.Mantzioris@unisa.edu.au \\ * Correspondence: Georgia.pollard@mymail.unisa.edu.au; Tel.: +61-8-8302-3000
}

Received: 7 September 2018; Accepted: 19 September 2018; Published: 20 September 2018

\begin{abstract}
We are living in an age of concern for mental health and wellbeing. The objective of the research presented in this paper is to investigate the perceived health, social value and happiness benefits of urban agriculture (UA) by focusing on home and community food gardens in South Australia. The results reported in this paper are from "Edible Gardens", a citizen science project designed to investigate the social value, productivity and resource efficiency of UA in South Australia. Methods include an online survey and in-field garden data collection. Key findings include: dominant home gardener motivations were the produce, enjoyment, and health, while dominant community gardener motivations were enjoyment, connection to others and the produce. Exploratory factor analysis revealed four key factors: Tranquillity and Timeout, Develop and Learn Skills, the Produce, and Social Connection. The key difference between home and community gardeners was an overall social connection. Although home gardeners did not appear to actively value or desire inter-household social connection, this does not mean they do not value or participate in other avenues of social connection, such as via social learning sources or by sharing food with others. The combined results from this research regarding health and wellbeing, social connection and happiness support the premise that engagement in home or community food gardening may provide a preventative or supportive role for gardener health and wellbeing, regardless of whether it is a conscious motivation for participation.
\end{abstract}

Keywords: urban agriculture; urban food production; health; mental health; wellbeing; South Australia; social capital; social value; home gardens; community gardens

\section{Introduction}

We are living in an age of concern over the mental health and wellbeing of people, including the growing population in modern urban areas. According to the World Health Organization, depression is now the leading cause of ill health and disability worldwide with more than 300 million people affected [1]. In Australia, each year, almost 1 in 5 Australians will experience a mental illness such as anxiety or depression, while $45 \%$ of Australians will experience a mental illness at some point during their lifetime [2]. The majority (69\%) of Australians now live in urban areas [3]. There is a growing realisation that connection to nature, which may be diminished in urban settings, makes important contributions to our mental health and wellbeing [4-8]. Social isolation, such as lacking 
regular social contact or support from friends or family, is another contributor to poor mental health [9]. Experiencing nature has been found to have prosocial effects by increasing feelings of generosity, kindness, and empathy towards others [4] by reducing personal feelings of anxiety [10], and because spending time outdoors in natural environments has a positive association with happiness [6,11].

Mental health is not just a societal concern but also a monetary one. Mental illness in Australia costs \$20-28 billion per year (2009-2013) [9,12]. With the growing realisation of the impact of mental health on wellbeing, the South Australia government recently released the South Australian Mental Health Strategic Plan 2017-2022 [13]. The Department for Health and Wellbeing has also partnered with the Department for Environment and Water to create the "Healthy Parks, Healthy People Initiative" [14] to encourage all South Australians to engage more with nature. This initiative has resulted in a promotional campaign called "Five Ways to Wellbeing with Nature", which urges people to practice five simple actions: Connect, Be Active, Keep Learning, Take Notice and Give. Each of these five actions can be practised not just in large natural spaces such as national parks or wilderness areas, but are also applicable to smaller urban green spaces such as parks or gardens [14].

Amid the different nature-based opportunities for supporting good mental health and wellbeing is gardening [15-17], and by extension, growing food [8]. Producing food and keeping urban livestock in and around the fringes of urban centres is known as urban agriculture (UA). There are many different forms of UA including home gardens, community gardens, allotments, school gardens, community orchards, land-sharing, and other UA businesses. Prior research has shown engagement in UA to improve mental health and wellbeing [18-20] by lessening feelings of depression and fatigue [19], supporting stress management [20], and encouraging social cohesion [18]. However, little research has focussed purely on the potential for home food gardens, the most common form of UA in Australia [21] to support mental health, wellbeing, and social capital. In part, this may be because of the difficulty of conducting research on home food gardens due to their sheer diversity, geographic spread and low physical accessibility and visibility [22-24]. It remains unclear whether the mental health benefits documented in other forms of UA (such as community gardens) are also present in home food gardens. There are of course many other forms of UA occurring in and around the fringes of urban centres, however, this study focusses purely on home and community food gardens. Recommendations for further research into food gardeners' motivations, barriers to participation (particularly for new gardeners), and what they perceive as the value of UA, have been strongly advocated by Nugent (2000), Petts (2005) and Wise (2014).

The aim of this paper is to investigate the perceived health, social value and happiness benefits of the UA, in particular, focusing on whether home gardeners obtain similar benefits as community food gardeners. South Australia is presented as an interesting case study due to its recent adoption of several mental health and wellbeing initiatives [13,14], and the high level of participation in urban food production in the state (59\% of the population) [25]. Previous work by Pollard, et al. [26] examined the diverse nature of UA in South Australia by reporting survey results on the physical, practical and economic aspects of home food gardens, stemming from a research project called "Edible Gardens". Building on that work, this paper includes results from two sources, both part of the Edible Gardens project: (1) responses to survey questions relating to the motivations, social value and social capital of UA, food preservation, and food distribution, and (2) results from in-field garden data collection tracking home-grown produce shared with others. The discussion focusses on the deeper motivations, meaning and value behind growing food, in addition to the many different avenues of social connection. Previous studies have shown that growing food at home may not be cost-effective on a purely economic basis, particularly when applying a wage-rate to invested labour [27-31]. The results of this paper are therefore of significance in the context of valuing the contribution made by home food gardens beyond productivity. 


\section{Materials and Methods}

"Edible Gardens" (EG) was a citizen science project designed to investigate the social value, productivity and resource efficiency of UA in South Australia. It was launched in late 2016 by the Discovery Circle-a citizen science initiative of the University of South Australia. The project received approval from the Human Research Ethics Committee of the University of South Australia in January 2016 (Protocol number 0000034940). Phase 1 of the Edible Gardens project was an online 'Survey Monkey' survey designed to ask food gardeners across South Australia about their motivations, values, challenges, learning sources, food preservation methods, food sharing and many other practical aspects of their food gardens. The survey included closed, open, category and ranking questions (for the full list of related survey questions please refer to the Supplementary Table S1). The project was promoted on the Discovery Circle website and Facebook page, and via other print materials and press releases from the project sponsors: The University of South Australia, the Department for Environment and Water, the Adelaide and Mount Lofty Ranges Natural Resources Management Board, the City of Salisbury and the City of Marion. From September 2016 to May 2018, 402 respondents completed the online survey. Each of the reported samples sizes presented in the results was determined by the number of responses to each survey question. Incomplete, skipped or non-applicable responses to particular questions were removed during data cleaning.

Part of the online survey was based on the Recreation Experience Preference (REP) Scale, originally developed by Driver [32] to measure experience preferences for national parks and wilderness areas. In Australia, the original REP scale was adapted by Weber and Anderson [33] to study the experience preferences of more urban parks and green areas. A REP-based scale of 30 individual Likert-style scale statements, focused on food production was used in the Edible Gardens survey (for the full list of REP scale statements used in this study, please refer to the Supplementary Table S2). Open-answer questions on what respondents valued about growing food were also included in the online survey, to provide a contrast to the modified REP scale.

The survey also investigated the social capital levels of the respondents. Social capital is defined by Martin, et al. [34] as "a measure of trust, reciprocity and social networks" and thus is suitable for UA research investigating the social connection between food gardeners. The quantitative seven-item Likert scale tool developed and validated by Sampson, et al. [35] to measure social capital levels was used. This tool was used in conjunction with additional questions recommended by Martin, Rogers, Cook, and Joseph [34], to ascertain any involvement in collective action activities, the presence of elderly household members, and both household and neighbourhood tenure. The median score of each respondent to the social capital questions was calculated before the median scores of home gardeners and community gardeners were grouped. If a respondent had participated in a group gardening activity, an additional point was added to their personal social capital score to create a 'total social capital score'.

Phase 2 of the Edible Gardens project involved data collection in participants' gardens. Of the survey participants, $58 \%$ volunteered to collect data on their own food gardens. A subset of these $(n=70)$ was selected to register their gardens, and more than half of those participants followed through with collecting and submitting garden data $(n=39)$. The participants were selected to ensure a broad range of garden setups and gardeners: garden sizes, production methods, costs (both set-up and ongoing costs), estimated time spent gardening, years of gardening experience and ages of the gardeners. For a full description of the project design please refer to Pollard, Roetman, and Ward [29]. Of relevance to this paper was the tracking of any portion of the garden harvest that participants shared with someone outside of their own household. Food gardeners also often experience periods of 'gluts' of a crop, where too much to consume is ready to harvest at one time [25,36,37], hence our consideration of food preservation and food distribution activities. Each gift or sharing of produce was weighed using a spring balance or digital scales, and the crop and recipient of the food were recorded (Recipients were categorised as family, friend, community, food swap or 'other'). Data analyses were 
conducted in a combination of Microsoft Excel 2016, IBM's SPSS Statistics Software V.25 and QSR NVivo Qualitative Analysis Software V.11.

\section{Results}

The results are divided into 2 sections: (1) the motivations, learning sources, values and social capital of home food gardeners; (2) food preservation practices and food distribution. These results combine both the Phase 1 survey data and the Phase 2 in-field data from the Edible Gardens project and build on previous work by Pollard, Ward and Roetman [26] who published the survey results relating to the physical, practical and economic aspects of the respondents' food gardens.

\subsection{Motivations, Values and Social Capital}

Survey respondents were asked in two ways about what motivated them to grow food. Initially, they were asked why they first decided to start growing some of their own food-their original motivations. Then they were asked to list the top three reasons they currently grew food-their ongoing motivations. These two questions allowed us to identify what draws people to grow food, and how these motivations persist or are replaced over time (Tables 1 and 2).

Table 1. The top 10 original and ongoing motivation categories of Edible Gardens home gardeners.

\begin{tabular}{|c|c|c|c|c|c|}
\hline \multicolumn{6}{|c|}{ Home Gardeners $(n=369)$} \\
\hline \multicolumn{2}{|r|}{ Original Motivations } & \multirow{2}{*}{$\begin{array}{c}\% \\
44 \% \\
\end{array}$} & \multicolumn{2}{|r|}{ Ongoing Motivations } & \multirow{2}{*}{$\begin{array}{c}\% \\
70 \%\end{array}$} \\
\hline 1 & Produce related (mostly taste \& freshness) & & 1 & Produce related (mostly taste \& freshness) & \\
\hline 2 & Enjoyment & $35 \%$ & 2 & and organic food) & $47 \%$ \\
\hline 3 & $\begin{array}{l}\text { Health (Mostly chemical input concerns } \\
\text { and organic food) }\end{array}$ & $32 \%$ & 3 & Enjoyment & $46 \%$ \\
\hline 6 & Tradition & $15 \%$ & 6 & Convenience & $21 \%$ \\
\hline 7 & Connection to others (mostly family) & $14 \%$ & 7 & Satisfaction \& accomplishment & $21 \%$ \\
\hline 8 & Satisfaction \& accomplishment & $14 \%$ & 8 & Environmental consideration & $18 \%$ \\
\hline 9 & Knowledge building & $14 \%$ & 9 & Connection to others (mostly family) & $17 \%$ \\
\hline 10 & Convenience & $13 \%$ & 10 & Knowledge building & $17 \%$ \\
\hline
\end{tabular}

Table 2. The top 10 original and ongoing motivation categories of Edible Gardens community gardeners.

\begin{tabular}{|c|c|c|c|c|c|}
\hline \multicolumn{6}{|c|}{ Community Gardeners $(n=20)$} \\
\hline \multicolumn{2}{|r|}{ Original Motivations } & \multirow{2}{*}{$\begin{array}{c}\% \\
35 \% \\
\end{array}$} & \multicolumn{2}{|r|}{ Ongoing Motivations } & \multirow{2}{*}{$\begin{array}{c}\% \\
70 \%\end{array}$} \\
\hline 1 & Enjoyment & & 1 & $\begin{array}{l}\text { Connection to others (mostly } \\
\text { community interaction) }\end{array}$ & \\
\hline 2 & $\begin{array}{l}\text { Connection to others } \\
\text { (community interaction) }\end{array}$ & $30 \%$ & 2 & $\begin{array}{l}\text { Produce related (mostly freshness, } \\
\text { taste and variety) }\end{array}$ & $47 \%$ \\
\hline 3 & Produce related (mostly taste and freshness) & $25 \%$ & 3 & Enjoyment & $46 \%$ \\
\hline 4 & Health (mostly organic food) & $20 \%$ & 4 & Natural connection & $27 \%$ \\
\hline 5 & $\begin{array}{l}\text { Environmental consideration } \\
\text { (carbon footprint) }\end{array}$ & $15 \%$ & 5 & Satisfaction and accomplishment & $25 \%$ \\
\hline 6 & Natural connection & $15 \%$ & 6 & Contribute to self-sufficiency & $21 \%$ \\
\hline 7 & Knowledge building & $10 \%$ & 7 & Health (mostly organic food) & $21 \%$ \\
\hline 8 & Satisfaction and accomplishment & $10 \%$ & 8 & Knowledge building & $18 \%$ \\
\hline 9 & To save money & $10 \%$ & 9 & Environmental consideration & $17 \%$ \\
\hline 10 & Tradition & $10 \%$ & 10 & To save money & $17 \%$ \\
\hline
\end{tabular}

The top four persistent motivations were related to produce, enjoyment, health (for home gardeners) and connections to others (for community gardeners). There was some shifting of the lesser ranked motivations over time for both sets of gardeners. The main differences in the motivations of home and community gardeners related to both the ranking and content of the 'Connection to others' motivation. For home gardeners, 'Connection to others' ranked 7th and 9th in the list of motivations 
and mostly referenced family and time with children. For community gardeners, 'Connection to others' ranked 2nd and 1st on their lists of motivations and mostly referenced community interaction. The motivation 'To save money' was ranked higher by home gardeners (5th and 4th) than by the community gardeners (9th and 10th). Other differences include 'Convenience' which ranked 10th and 6th for home gardeners but did not appear in the top ten for community gardeners, and the 'Health' motivation contained differently coded content, with home gardeners mostly referencing chemical or input concerns and organic food, while the community gardeners mostly referenced just organic food. While 'Health' did shift down the list of ongoing motivations, it did retain a similar percentage over time.

Respondents were also asked from where, or from whom they learned about food gardening (Figure 1). The more inherently social learning sources appear in the lower half of Figure 1. Most respondents (57\%) learned from two or three social learning sources and three less-social sources $(51 \%)$. Greater numbers of social learning sources positively correlated with greater numbers of production methods (Spearman correlation: $r_{\mathrm{S}}=0.246$ ), gardening approaches (Spearman correlation: $\left.r_{\mathrm{S}}=0.326\right)$ and irrigation methods (Spearman correlation: $r_{\mathrm{S}}=0.204$ ), in addition to higher gardening consistency (Spearman correlation: $r_{\mathrm{s}}=0.219$ ) and giving food to more groups of people (Spearman correlation: $r_{\mathrm{s}}=0.235$ ). A Spearman correlation is a non-parametric test for assessing the relationship between two samples [38]. Both the terms 'production methods' and 'gardening approaches' have been defined and described in a previous paper [26]. 'Production methods' relate to the different physical methods to grow food, for example, in-ground beds or raised beds, while 'gardening approaches' relate to the grouping of the more theoretical approaches to growing food, for example, organic, permaculture or companion planting.

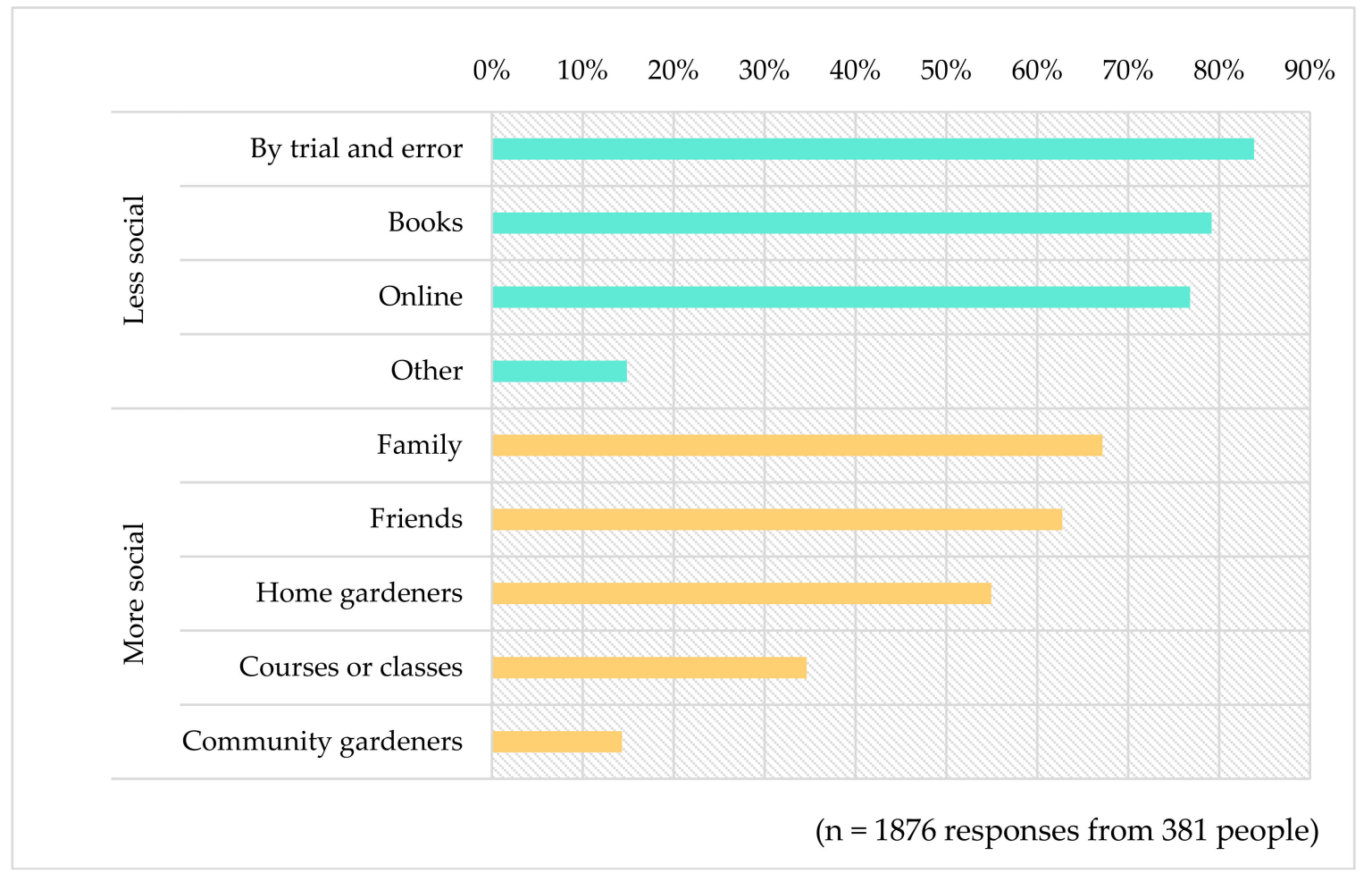

Figure 1. The responses to the question, "from where have you learned about food gardening?" The 'other' category mostly refers to sources such as TV shows, magazines or radio. Please note the responses were not mutually exclusive. 


\subsubsection{Values}

Exploratory Factor Analysis using Principal Axis Factoring with Varimax Rotation and Kaiser Normalisation was applied to 27 of the 30 REP scale statements $(n=372)$ (Table 3). Three of the statements were removed from the list of REP scale items as they did not load strongly onto any factors. These statements were, "I produce food to spend time with my family", "I produce food to spend time without my family" and "I produce food to save money". Ten items cross-loaded onto more than one factor; however, only two of those items had secondary loadings close to the loadings on their dominant factors. With Principal Axis Factoring the higher the value of each variable (in this case - statement) the stronger the loading on the factor. Four factors emerged from the analysis: (1) Tranquillity and Timeout, (2) Develop Skills and Learn, (3) The Produce and (4) Social Connection.

Table 3. Item loading from Principal Axis Factoring with Varimax Rotation and Kaiser Normalisation.

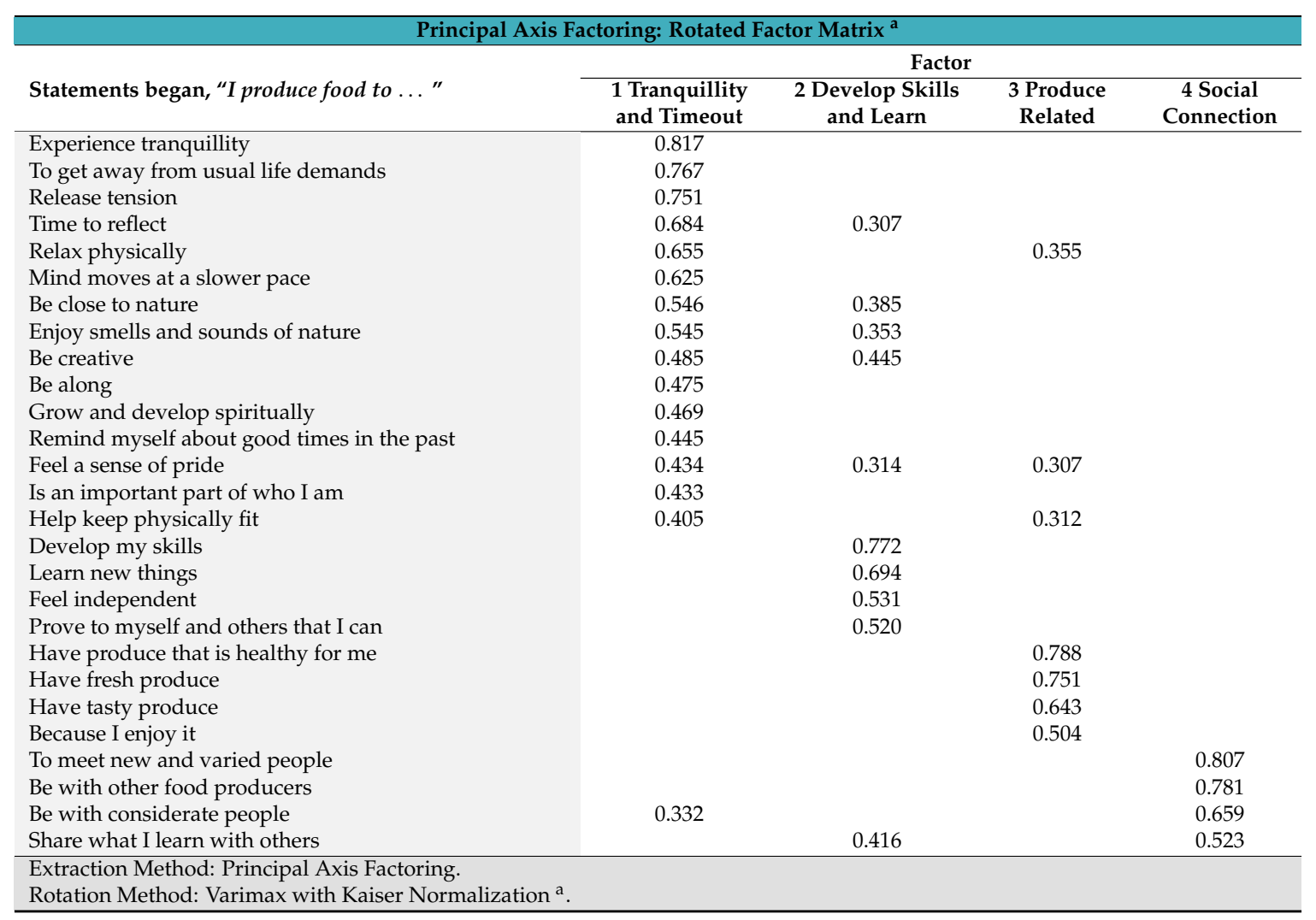

${ }^{\text {a }}$ Rotation converged in 7 iterations.

Each factor was assessed for their corresponding level of agreement for both home gardeners $(n=355)$ and community gardeners $(n=17)$ (Table 4$)$. This assessment was done by combining the mean scores of the statements related to each factor for each respondent. Thus, each respondent had a score for each factor. The agreement levels for the four factors differ somewhat between home and community gardeners. Community gardeners have a slightly higher level of agreement with Factor 2 (Develop Skills and Learn), whereas home gardeners have a stronger agreement with Factor 3 (The Produce). The main difference, however, is Factor 4 (Social Connection), with the mean response of home gardeners being 'Disagree to Neutral' (2.77), while the mean response of community gardeners is 'Neutral to Agree' (3.54). 
Table 4. The comparison of the home and community gardener level of Factor agreement. The colour coding is as follows: yellow for neutral-agree, red for disagree-neutral and green for agree-strongly agree.

\begin{tabular}{|c|c|c|c|c|c|}
\hline \multirow[b]{2}{*}{ Factor } & \multicolumn{2}{|c|}{ Home Gardeners $(n=355)$} & \multicolumn{2}{|c|}{ Community Gardeners $(n=17)$} & \multirow[b]{2}{*}{$\begin{array}{l}\text { Difference } \\
\text { in Means }\end{array}$} \\
\hline & Mean & $\begin{array}{c}\text { Level of } \\
\text { Agreement }\end{array}$ & Mean & $\begin{array}{c}\text { Level of } \\
\text { Agreement }\end{array}$ & \\
\hline 1: Tranquillity and Timeout & 3.88 & Neutral-Agree & 3.84 & Neutral-Agree & 0.04 \\
\hline 2: Develop Skills and Learn & 3.73 & Neutral-Agree & 3.94 & Neutral-Agree & 0.21 \\
\hline 3: The Produce & 4.70 & $\begin{array}{c}\text { Agree-Strongly } \\
\text { Agree }\end{array}$ & 4.35 & $\begin{array}{c}\text { Agree-Strongly } \\
\text { Agree }\end{array}$ & 0.35 \\
\hline 4: Social Connection & 2.77 & Disagree-Neutral & 3.54 & Neutral-Agree & 0.77 \\
\hline
\end{tabular}

Each factor was analysed for correlations with other variables, including gardening consistency, the total number of production methods, gardening experience, years lived in the current house, and the number of social learning sources. Factor 4 (Social Connection) was the only factor to return significant results. Respondents with higher Social Connection values had larger gardens (Spearman correlation: $r_{s}=0.235$ ), greater gardening consistency (Spearman correlation: $r_{s}=0.249$ ), shared food with more different groups of people (Spearman correlation $r_{s}=0.232$ ), believed they saved greater proportions of their weekly fruit and vegetable budget (Spearman correlation: $r_{s}=0.336$ ) and agreed more with the statement, "I produce food to save money" (Spearman correlation: $r_{s}=0.209$ ).

\subsubsection{Social Capital}

The original social capital scores ranged from zero to five; home gardeners $(n=336)$ were asked questions about their neighbourhood, while community gardeners $(n=18)$ were asked questions about their community garden. Out of five, home gardeners had a median score of three, while community gardeners had a median score of four. When also considering the involvement or lack therefore of respondents in group gardening activities (such as working bees, garden tours, harvest parties or swap meets) the difference between home and community gardeners became more pronounced. Of the home gardeners, $44 \%$ had participated or organised a group gardening activity, whereas this was $83 \%$ of community gardeners. Indeed the community gardeners were found to have higher 'total social capital scores' (a combination of their median social value scores with an additional point added for any involvement in group gardening activities), than home gardeners (Mann-Whitney $\mathrm{U}=5123, \mathrm{n}_{1}=20$ (community gardeners), $\mathrm{n}_{2}=355$ (home gardeners), $\mathrm{P}=0.001, r=0.22$ ). The Mann-Whitney $\mathrm{U}$ test is a nonparametric test of the difference between two unrelated samples [38]. No relationship was found between household social capital scores and the presence of either an elderly family member (over 65), or young children (primary school age or younger), nor was there any relationship found between social capital scores and the respondents' age, how long they had lived in their house or neighbourhood, how frequently they share food, or with any of the four factors. The median length of time the respondents had lived in their house was eight years, while the median length of time lived in their neighbourhood was nine years.

\subsection{Food Preservation Practices and Food Distribution}

How people use their harvested produce is an important aspect of their food gardening activities. Other than immediately consuming it, food gardeners can either preserve food or distribute some of what they grow to others. When the EG survey respondents were asked whether they experience gluts of crops, $73 \%$ either 'Agreed' or 'Strongly Agreed' $(n=367)$. The respondents were asked to select all the food processing, storing, or preserving techniques they had used within the last year (Figure 2). Seventy percent of the respondents made use of three or more different preservation techniques. Respondents were not asked about food waste, but some did mention trying to avoid food waste in response to the question about why they did or did not store, process or preserve harvested food (Table 5). 


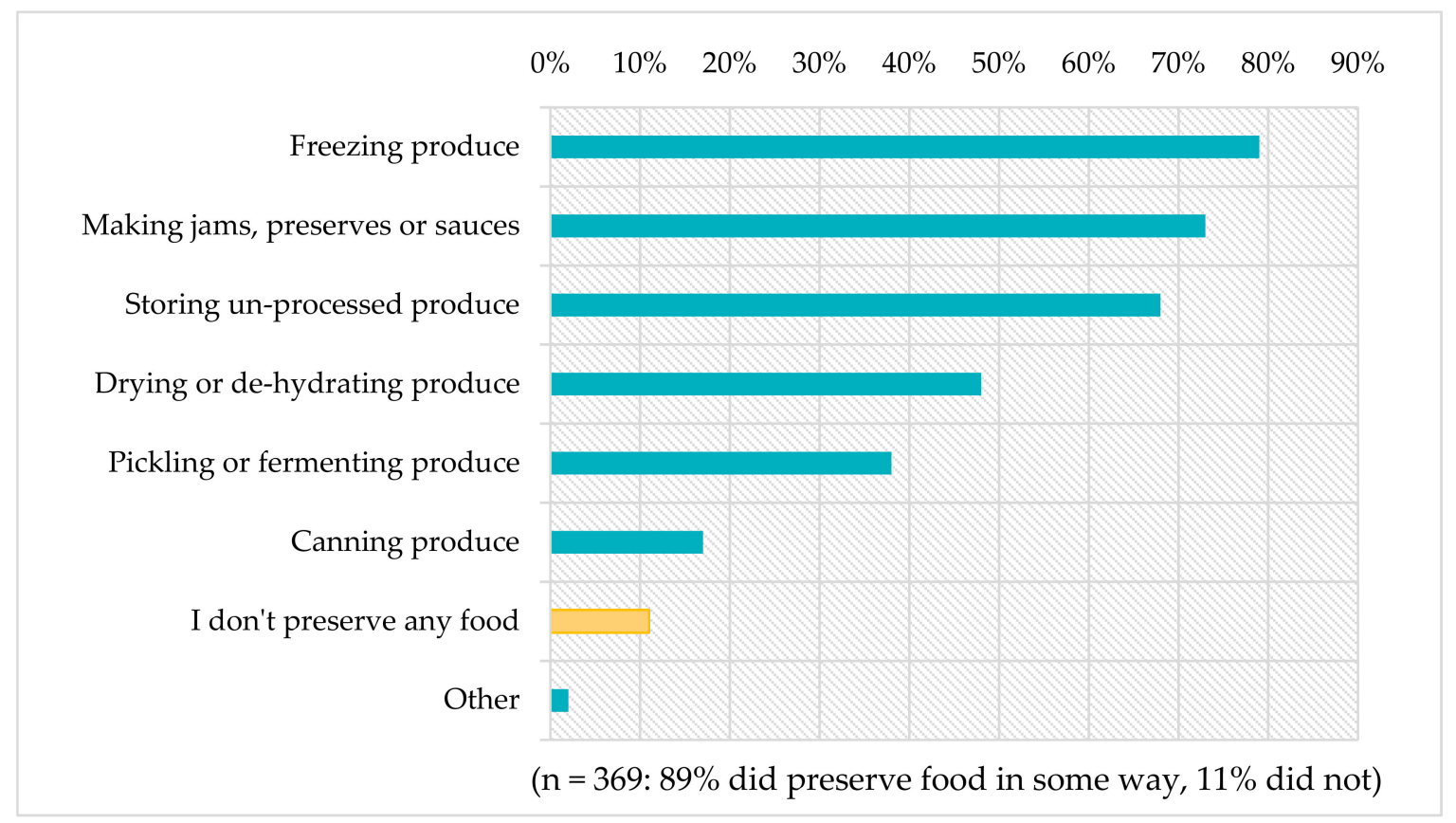

Figure 2. The food processing, storing or preserving techniques used by Edible Gardens survey respondents in the past year. 'Other' mostly refers to other uncommon methods, for example, salting olives or making wine, beer and cordial. The options were not mutually exclusive.

Table 5. The reasons to and to not store, process or preserve harvested food.

\begin{tabular}{|c|c|c|c|}
\hline \multicolumn{4}{|c|}{ Storing, Processing and Preserving Food } \\
\hline Reasons to Store, Process or Preserve Food $(n=302)$ & $\%$ & Reasons Not to Store, Process or Preserve Food $(n=35)$ & $\%$ \\
\hline $1 \quad$ Use at a later date & $28 \%$ & $1 \quad$ Prefer it fresh or consume it all fresh & $37 \%$ \\
\hline Avoid waste & $19 \%$ & Give any excess away & $34 \%$ \\
\hline Use in cooking & $12 \%$ & Don't grow enough & $26 \%$ \\
\hline Overcome a glut of food & $9 \%$ & & \\
\hline The process is interesting and/or enjoyable & $8 \%$ & & \\
\hline $\begin{array}{l}\text { Total percentage of those did store, process or preserve } \\
\text { food in some way }\end{array}$ & $89 \%$ & $\begin{array}{l}\text { Total percentage of those who do not store, process or } \\
\text { preserve food }\end{array}$ & $11 \%$ \\
\hline
\end{tabular}

The number of food processing, storing or preservation methods used by the respondents positively correlated with several other variables. Gardeners who used more of these methods were also likely to use a greater number of theoretical gardening approaches (e.g., organic, permaculture, companion planting) (Spearman correlation: $\left.r_{s}=0.215\right)$, use a greater number of different physical production methods (e.g., raised garden bed, wicking bed, pots or planters) (Spearman correlation: $r_{s}=0.244$ ), to spend more hours per week growing food (Spearman correlation: $r_{s}=0.225$ ), to have greater gardening consistency (Spearman correlation: $r_{S}=0.215$ ), to believe they save more money (Spearman correlation: $r_{s}=0.249$ ) and finally, to give food to more groups of people (Spearman correlation: $\left.r_{s}=0.239\right)$.

\section{Food Distribution}

The survey respondents were asked whether they share, gift or donate food they grow to others outside of their household. Most respondents said yes (95\%), while only $5 \%$ said no. Those who said no were asked why (open-ended question; $n=21$ ) with the most common response being, they "Don't grow enough" (70\%).

Those respondents who said yes to food sharing were asked about the frequency of their sharing and who they gave food to (Figure 3). While friends were the most commonly reported recipient of food sharing $(42 \%)$, a total of $59 \%$ of respondents reported giving food away to three or more different groups of recipients. Sharing food to a greater number of recipients was correlated with greater 
numbers of theoretical gardening approaches (Spearman correlation: $r_{s}=0.222$ ), greater numbers of physical production methods (Spearman correlation: $r_{s}=0.288$ ), greater year-round gardening consistency (Spearman correlation: $r_{s}=0.228$ ) and the belief that they saved more money by producing food (Spearman correlation: $r_{s}=0.238$ ). Those respondents who said yes to food sharing were also asked whether they purposefully grew extra food to share it with others. This question elicited quite a different response, with only $36 \%$ answering 'yes', and $64 \%$ answering 'no'.

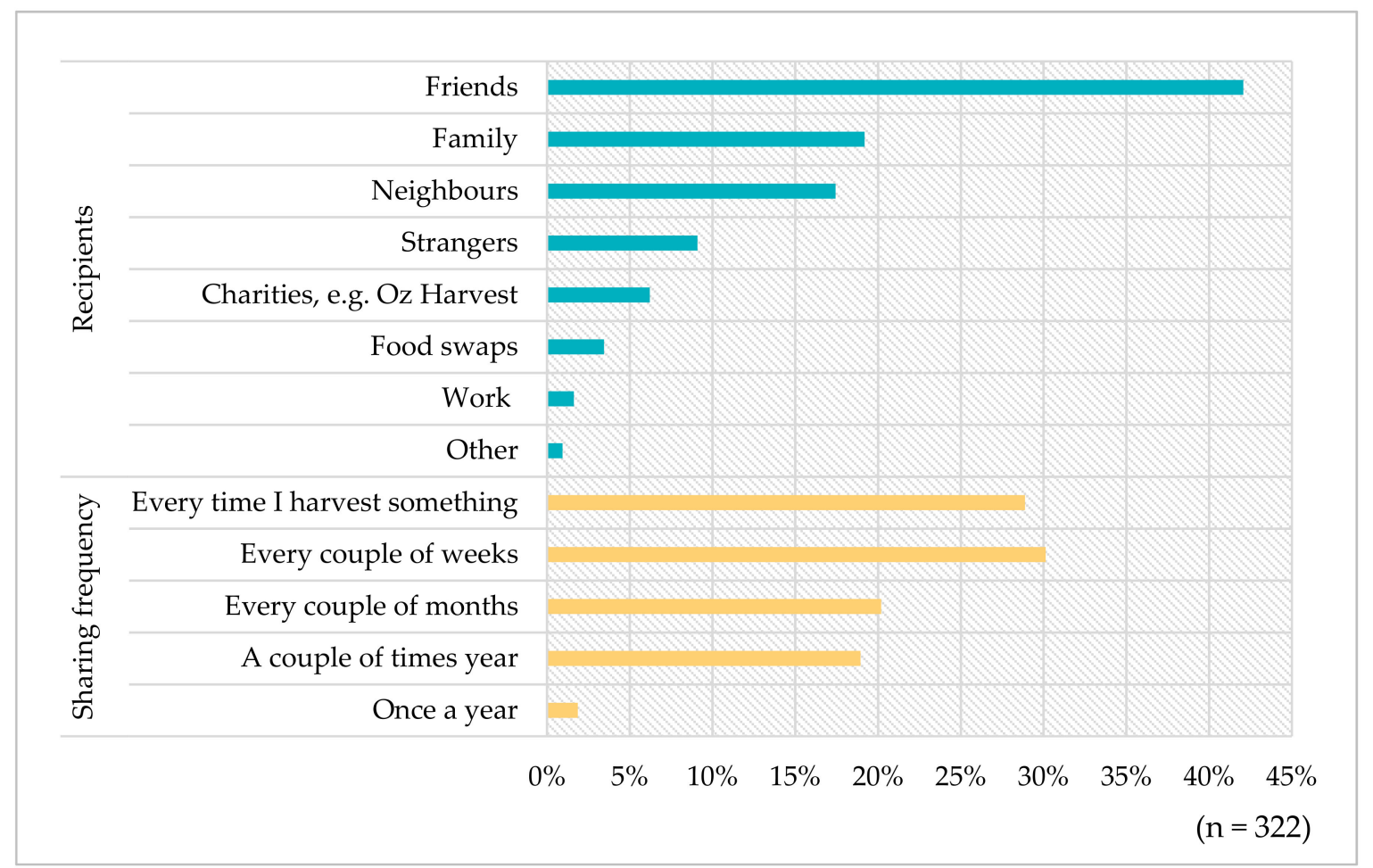

Figure 3. The reported recipients and frequency of food sharing by Edible Gardens project survey respondents. The 'other' recipients refer mostly to selling produce to local cafes or businesses and giving food away to anyone they come in contact with.

As part of the Phase 2 garden data collection, selected participants not only weighed and recorded the different crops they grew, but also recorded, weighed and tracked any food they gave away to others outside of their own household, including who they gave it to. Of the $4202 \mathrm{~kg}$ of produce grown and recorded, $12 \%(501 \mathrm{~kg})$ was given away to others. The proportions of food given away to others included $50 \%$ to family, $48 \%$ to friends, $1 \%$ to both the community and 'other', and less than $1 \%$ to food swaps. The food which was given away can be categorised by type: Vegetables, Fruits, Animal Products and Herbs (Table 6). Regarding the frequency of produce sharing of the Phase 2 participants, the majority $(87 \%)$ of food sharing was occurring at least every couple of weeks, with a further $9 \%$ of the sharing occurring every couple of months and 3\% occurring a couple of times a year. 
Table 6. Tracked food sharing by produce category by EG participants $(n=39)$ during Phase 2 of the EG project.

\begin{tabular}{lccc}
\hline Shared Produce Categories & $\begin{array}{c}\text { \%o of the Total } \\
\text { Harvest Which } \\
\text { Was Shared } \\
\text { (by Category) }\end{array}$ & $\begin{array}{c}\text { Most Common Foods/ } \\
\text { (by Category) in kg }\end{array}$ & $\begin{array}{c}\text { \% of Shared } \\
\text { Category }\end{array}$ \\
\hline 1. Vegetables & $55 \%$ & Zucchini $(80 \mathrm{~kg})$ & $34 \%$ \\
& & Tomatoes $(54 \mathrm{~kg})$ & $23 \%$ \\
2. Fruits & $28 \%$ & Nectarines $(24 \mathrm{~kg})$ & $20 \%$ \\
3. Animal Products & $15 \%$ & Peaches $(19 \mathrm{~kg})$ & $16 \%$ \\
4. Herbs & $2 \%$ & Chicken eggs $(89 \mathrm{~kg})$ & $100 \%$ \\
\hline
\end{tabular}

\section{Discussion}

The following discussion is split into three parts: (1) the motivations and value of growing food, (2) the social value of growing food, and (3) the implications for health and wellbeing.

\subsection{The Motivations and Value of Growing Food in Urban Areas}

The dominant motivations for our home gardeners were the produce (mostly taste and freshness), enjoyment, and health (mostly chemical input concerns and interest in organic food). As comprehensively reviewed by Kiesling and Manning [39], past research into general gardener motivations supplies the following categories: creative expression, health promotion, production, skill-building, and knowledge enhancement, connection to nature, perceived social benefits and as an expression of faith. The majority of both the original and ongoing motivations reported by the EG survey respondents fall into these listed categories (Tables 1 and 2). The few reported motivations not strictly adhering to these categories are saving money, convenience, satisfaction and accomplishment, and enjoyment. Satisfaction and accomplishment may be linked to the listed category of skill-building, and knowledge enhancement, and it is possible that enjoyment fits into the category of creative expression. But both saving money and convenience appear to remain motivations unique to the practical and productive nature of producing food.

Curiously, both natural connections and environmental considerations were reported by reasonably low percentages of both home and community gardeners. Although ranked 4th and 5 th by home gardeners and 6th and 4th by community gardeners, the natural connection was only reported by $15-25 \%$ of the total combined survey respondents. Environmental consideration was ranked 11th (just off the list of the top 10 categories) and 8th by home gardeners and 5th and 9th by community gardeners yet was only reported by $12-15 \%$ of the total combined survey respondents (Tables 1 and 2). 'Environmental consideration' consisted of references to carbon, food miles, local food, helping the world, sustainability and waste, compost and recycling. A much stronger reference to environmental consideration came from the question of why people store, process or preserve food, with the second highest reason being 'to avoid waste' (19\%). Indeed, future research could investigate whether self-grown food is more highly valued than store-bought food and whether self-grown food is, therefore, wasted less.

\subsection{The Social Value of Growing Food in Urban Areas}

Growing food at home is not always perceived as an inherently social activity, particularly when compared to community gardening. Yet multiple avenues for social connection, value and interaction can be recognised in home gardeners in this study. The first avenue of social connection is via learning sources. The EG survey participants were asked to select all the sources from which they gained knowledge about growing food $(n=381)$. Out of the nine possible sources, five of them were categorised as 'social' sources-typically from face-to-face interactions (Figure 1). The remaining four 
sources were categorised as 'less-social' sources-typically lacking face-to-face interactions. Learning from family $(65 \%)$ and friends $(62 \%)$ were the two highest listed social learning sources. These results match that of Kiesling and Manning [39], who found that $60 \%$ of their respondents reported that their interest in gardening stemmed from the influence of a relative, friend or neighbour. The greater the number of social learning sources someone had, the more likely that person was to use a greater number of production methods, gardening approaches, irrigation methods, give food to more groups of people and have greater gardening consistency. In short, it appears that additional social learning sources inspire greater diversity in our respondent's food gardens.

The survey also investigated the social capital levels of the respondents. Community gardens have been found to assist in increasing the social capital of members [40,41], while the relationship between home food gardens and social capital is less understood. Galhena, et al. [42] considered the value of interactions between home gardeners and the community within indigenous cultures. Although a more individual activity, home gardeners did interact with the broader community with exchanges or gifts of produce. It is these interactions that can contribute to the building of social capital [42]. The lack of statistical relationship found between household social capital scores and the presence of either an elderly family member (over 65), or young children (primary school age or younger) differs greatly from the results by Martin, Rogers, Cook, and Joseph [34]. We did find, however, that our community gardeners were almost twice as likely to have participated or organised a group gardening activity. By incorporating any involvement in a group gardening activity to each respondent's social value score, the difference in social capital levels between the community and home gardeners became more pronounced with our community gardeners having higher levels of total social capital.

There is a substantial difference in the intra-household and inter-household social connections between home and community gardeners. 'Social connection' was listed as one of the top ten original and ongoing motivations for the home and community survey respondents. The difference lies in what 'social connection' meant to each group. For home gardeners, 'social connection' referred mostly to family and children - an intra-household social connection. These connections were categorised as social during our analysis yet may not be considered particularly 'social' by the home gardeners themselves. For community gardeners, however, 'social connection' referred mostly to community interaction-inter-household social connections. This contrast is further emphasised by the rating of Factor 4 (Social connection), which elicited a "Disagree to Neutral" response (mean $=2.77$ out of 5) from home gardeners and a "Neutral to Agree" response (mean $=3.54$ out of 5) from community gardeners. These results suggest that, in general, our home gardeners do not actively value or desire inter-household social connection through food gardening. This finding corresponds with the work by Wise [21] who found that only $2 \%$ of gardeners reported community participation or making friends as reasons to grow their own food.

\subsection{Food Preservation and Distribution}

As the majority of the EG survey respondents either 'Agreed' or 'Strongly Agreed' that they experienced gluts of crops, there are opportunities for activities with surplus produce. Learning to preserve and store produce is a practical way to even out crop availability [25,31]. Beyond the practical aspects of food preservation, Click and Ridberg [43] found that food preservation can also be a way to strengthen relationships and connections in addition to being a strong source of empowerment. As most of their participants were taught preservation techniques by a family member or friend, or practised the technique as a family event, these practices often evoked strong emotional memories and responses [43].

The EG survey respondents were quite prolific with their use of food preservation methods, with $70 \%$ using two or three methods in a year. The most common methods were freezing produce $(79 \%)$, making jams, preserves or sauces $(73 \%)$ and dry storing produce $(68 \%)$. Although the sharing of 
preserved foods was not tracked during the EG project, such products are also likely to be shared, as fresh produce is, with others outside of the grower's household.

Fresh or preserved produce can also be gifted, donated or distributed to others outside of the grower's household. Sharing produce has typically been reported as a low motivator for food gardeners in developed countries [21,23,44], and indeed it did not appear in our lists of either original or ongoing motivations. While it may not be a motivation for people, it certainly appears to be a frequent outcome of growing food. Vitiello, Nairn, Grisso and Swistak [36] were surprised when nearly all their community garden participants reported sharing their produce with those who were hungry. The strong majority of EG survey respondents reported sharing food frequently with a range of people. During Phase 2 of the EG project, our participants weighed and tracked the amount of food they shared with others outside of their own gardens ( $12 \%$ of the total harvest). The different reported crop categories (vegetables, fruits, animal products, and herbs) can carry a very different value (both monetary and dietary) per kilogram, thus the crude proportioning of produce sharing by weight alone only tells part of the story of generosity. Sharing with family was reported at a higher rate during Phase 2 garden data collection than was estimated by survey respondents as part of Phase 1. Other studies to weigh and track proportions of harvests shared with others (as part of larger UA yield studies) include Algert, et al. [45], Conk [46], Pourias, et al. [47], and Zainuddin and Mercer [37]. These studies all reported greater percentages of food shared with others, between 17\% to $35 \%$ of their total harvests. The most similar finding was by Algert, Baameur, Diekmann, Gray, and Ortiz [45] who found that although their 12 gardeners shared an average of 30\% of their total harvest. The recipients and proportions shared in that study were consistent with our findings from the EG project. Fifty percent of their participants shared produce went to family, $43 \%$ to friends and $3 \%$ to both charities and co-workers.

Most of the EG survey respondents stated that they did not purposefully grow extra food to share it. The contrast between those who reported sharing food $(95 \%)$ and those who say they do not grow extra food to share on purpose (64\%) could either attest to people's generosity, to their lack of awareness of the quantity of food their gardens produce, or to the lack of reliability of their food production-resulting in a large harvest one year and a low harvest the next. These findings are in agreement with the work of Kortright and Wakefield [23] who established that the majority of their gardeners purposely chose not to grow more food than they believed their own household could consume. Yet their remaining participants reported purposely growing and sharing their excess produce to initiate and maintain social relationships with others [23].

The EG gardeners' sharing of food typifies the growing awareness and popularity in South Australia of giving free excess food away to others. Other examples of this South Australian generosity include 'Grow Free' and 'Ripe Near Me'. Grow Free is a recent South Australian initiative of carts placed in public places where people can leave fresh produce, seeds, and seedlings to give away to others. The items are not valued in any way. There is no swapping, bartering or prices, people simply give what they can and take what they need. As of April 2018, there were 137 Grow Free carts listed across South Australia (http:/ / www.growfree.org.au/our-story/). Ripe Near Me was started in 2012 by two Adelaide based 'foodies' (people with a particular interest in food). They wanted to create a website to help people connect, find, grow, share and sell fresh and very local produce. The site hosts a map covered in different markers pinpointing the locations and describing the ripeness of available foods. Anyone can register to post produce they have grown themselves, or even produce they have spotted growing in other locations (https:/ / www.ripenear.me/). While urban food producers should still endeavour to improve their ability to produce food effectively and predictably, the various channels enabling food distribution means the wider community can benefit from inevitable food surpluses.

\subsection{Implications for Health and Wellbeing}

'Health' was listed as one of the dominant motivations of the survey respondents, referring mostly to concerns over chemical inputs and interest in organic foods. In addition, Factor 3 (The Produce) 
related strongly to valuing produce which was healthy, fresh and tasty. The healthiness of the food grown was a strong consideration of our survey respondents. The practical merits of this valued "healthiness" have also been reported to improve the dietary intake of fresh produce and improve nutrition from participation in community gardens [48,49] and home gardens [23].

While several of the EG survey motivations reference mental health and wellbeing, these considerations were not rated particularly highly in either the original or ongoing motivations. Yet there is a difference between a motivation for a behaviour and an outcome or benefit from a behaviour. Of the four value factors identified, Factor 1 (Tranquillity and Timeout) is inherently related to mental health and wellbeing. Key value statements in Factor 1 reference tranquillity, getting away from usual life demands, releasing tension, time to reflect, relaxing physically, the mind moving at a slower pace and connection to nature. Both the home gardeners and community gardeners rated this factor similarly and reasonably highly at 3.88 out of 5 and 3.84 out of 5 respectively (these scores sit at the higher range of the 'Neutral to Agree' level of agreement).

Another factor in the potential to relate to mental health and wellbeing is Factor 4 (Social Connection). As discussed above, the social connection factor was valued more highly by the community gardeners than by the home gardeners. Nevertheless, this does not mean that home gardeners do not value or participate in other avenues of social connection, for example, via the social learning sources or food distribution. Indeed Walsh [50] found growing food to be both a connection to gardeners' childhoods and a contributor to each gardener's sense of identity.

The final aspect of this research related to health and wellbeing is happiness. Enjoyment was another of the dominant motivations for the survey respondents, with many descriptions of love, happiness, and contentment. This speaks to past research where gardens, in general, are described as 'labours of love' [51]. Indeed in the study based in Florida, USA, by Zahina-Ramos [52], feelings of happiness, relaxation, and satisfaction were more highly valued than the produce itself. Experiencing nature has already been found to have a positive relationship with happiness [6,11]. Our results suggest that a similar relationship is possible within urban food gardens.

The combined results from this research regarding health and wellbeing, social connection and happiness support the premise that engagement in home or community food gardening may provide a preventative or supportive role for gardeners' health and wellbeing, regardless of whether it is a conscious motivation for participation. Soga, Cox, Yamaura, Gaston, Kurisu, and Hanaki [18] and Wood, Pretty and Griffin [19] also advocate engaging in urban agriculture as a form of preventative healthcare: encompassing general health, mental health, and social health. We recommend two key areas for future research, (1) food waste and whether self-grown food is more highly valued than store-bought food and thus is wasted less, and (2) how the non-monetary benefits of UA compare with the costs or benefits of food gardening measured in other ways, such as productivity.

\section{Conclusions}

Outwardly, the EG home gardeners were predominately motivated by the produce, health, and enjoyment, while the EG community gardeners were more motivated by enjoyment, connection to others and the produce. Of the other top ten motivations, saving money and convenience were the two found to be unique to the productive and practical nature of producing food.

The social connection was the greatest difference between the home and community gardens, with community gardeners being more strongly motivated by social connection with people outside of their own households. The community gardeners were found to have higher levels of total social capital than home gardeners and were approximately twice as likely to engage in a group gardening activity. Although home gardeners did not appear to actively value or desire inter-household social connection through food gardening, this does not mean they do not value or participate in other avenues of social connection, such as via social learning sources or by sharing food with others. Greater numbers of social learning sources were also found to inspire greater garden diversity. With regards to sharing food with others, $95 \%$ of the survey participants reported sharing food with others, although the 
majority (64\%) did not set out to grow food to share. Of the Phase 2 participants who collected data on their own food gardens, a total of $501 \mathrm{~kg}$ (12\% of everything they grew) was given away, typically every couple of weeks, to family, friends and the community. The wide range of channels facilitating sharing of surplus food provides growers with unpredictable yields or surplus harvests to contribute to the wider community.

Although mental health and wellbeing did not rate particularly highly as either an original or an ongoing motivation for our gardeners, there is a suggestion of deeper values as evidenced by the presence of factor items related to Tranquillity and Timeout (Factor 1). This, together with the overt sociability of community gardeners, the 'subtle sociability' of home gardeners (via social learning sources and food distribution), the strong valuing of both health and enjoyment, and the demonstrations of generosity, lead us to believe that participating in home or community food gardening may act as a supporting or preventative mechanism for resilient health and wellbeing.

Supplementary Materials: The following are available online at http:/ / www.mdpi.com/2413-8851/2/4/97/s1, List S1: List of relevant survey questions used in the EG online survey; List S2: List of REP items used in the EG project online survey.

Author Contributions: Conceptualization, Methodology \& Investigation by G.P., J.W. and P.R.; Formal Analysis by G.P., J.W., P.R. and B.C.; Writing-Original Draft Preparation by G.P.; Writing-Review \& Editing by G.P., J.W., P.R., E.M. and B.C.; Supervision by J.W. and P.R.; Funding Acquisition by P.R.

Funding: This research was funded by the University of South Australia, the South Australian Department for Environment and Water, the Adelaide and Mount Lofty Ranges Natural Resources Management Board, the City of Salisbury and the City of Marion.

Acknowledgments: We are grateful to all the South Australian gardeners for their participation in this study. We thank Andrew Royal for his development of the online infrastructure, and Hayley Tindle for help with survey design and administration.

Conflicts of Interest: The authors declare no conflict of interest. The funders had no role in the design of the study; in the collection, analyses, or interpretation of data; in the writing of the manuscript, and in the decision to publish the results.

\section{References}

1. World Health Organization. Fact Sheet: Depression; World Health Organization (WHO): Geneva, Switzerland, 2017; p. 4.

2. Australian Bureau of Statistics (ABS). National Survey of Mental Health and Wellbeing: Summary of Results, 2007; Cat No. 4326.0; Australian Bureau of Statistics, Commonwealth of Australia: Canberra, Australia, 2008.

3. Australian Bureau of Statistics (ABS). Australian Social Trends, April 2013: The 'Average' Australian; Cat. No 4102.0; Commonwealth of Australia: Canberra, Australia, 2013.

4. Capaldi, C.; Passmore, H.; Nisbet, E.; Zelenski, J.; Dopko, R. Flourishing in nature: A review of the benefits of connecting with nature and its application as a wellbeing intervention. Int. J. Wellbeing 2015, 4. [CrossRef]

5. Korpela, K.; Borodulin, K.; Neuvonen, M.; Paronen, O.; Tyräinen, L. Analyzing the mediators between nature-based outdoor recreation and emotional welbeing. J. Environ. Psychol. 2014, 37, 1-7. [CrossRef]

6. MacKerron, G.; Mourato, S. Happiness is greater in natural environments. Glob. Environ. Chang. 2013, 23, 992-1000. [CrossRef]

7. Soga, M.; Gaston, K.J. Extinction of experience: The loss of human-nature interactions. Front. Ecol. Environ. 2016, 14. [CrossRef]

8. Uhlmann, K.; Lin, B.; Ross, H. Who Cares? The Importance of Emotional Connections with Nature to Ensure Food Security and Wellbeing in Cities. Sustainability 2018, 10, 1844. [CrossRef]

9. Australian Bureau of Statistics (ABS). Australian Social Trends, March 2009; Cat. No 4102.0; Australian Bureau of Statistics, Commonwealth of Australia: Canberra, Australia, 2009.

10. Martyn, P.; Brymer, E. The relationship between nature relatedness and anxiety. J. Health Psychol. 2016, 21, 1436-1445. [CrossRef] [PubMed]

11. Zelenski, J.; Nisbet, E. Happiness and feeling connected: The distinct role of nature relatedness. Environ. Behav. 2014, 46, 3-23. [CrossRef] 
12. Medibank Private Health Insurance; Nous Group. The Case for Mental Health Reform in Australia: A Review of Expenditure and System Design; Medibank Private Limited and Nous Group: Melbourne, Australia, 2013; p. 120.

13. Government of South Australia. South Australian Mental Health Strategic Plan 2017-2022; South Australian Mental Health Commission, Government of South Australia: Adelaide, Australia, 2017; p. 48.

14. Government of South Australia. Healthy Parks, Healthy People South Australia 2016-2021: Making Contact with Nature, Second Nature; Department of Environment, Water and Natural Resources and the Department of Health and Ageing, Government of South Australia: Adelaide, Australia, 2016; p. 52.

15. Freeman, C.; Dickinson, K.; Porter, S.; van Heezik, Y. "My garden is an expression of me": Exploring householders' relationships with their gardens. J. Environ. Psychol. 2012, 32, 135-143. [CrossRef]

16. Buck, D. Gardens and Health: Implications for Policy and Practice; National Gardens Scheme: London, UK, 2016; p. 65. Available online: https://www.kingsfund.org.uk/publications/gardens-and-health (accessed on 1 June 2018).

17. Clatworthy, J.; Hinds, J.; Camic, P. Gardening as a mental health intervention: A review. Ment. Health Rev. J. 2013, 18, 214-225. [CrossRef]

18. Soga, M.; Cox, D.T.C.; Yamaura, Y.; Gaston, K.J.; Kurisu, K.; Hanaki, K. Health benefits of urban allotment gardening: Improved physical and psychological well-being and social integration. Int. J. Environ. Res. Public Health 2017, 14, 71. [CrossRef] [PubMed]

19. Wood, C.J.; Pretty, J.; Griffin, M. A case-control study of the health and well-being benefits of allotment gardening. J. Public Health 2016, 38, 336-344. [CrossRef] [PubMed]

20. Maheshwari, S. Food in the city: Review of psychological impact of growing food in urban spaces. Int. J. Environ. Res. Public Health 2017, 14, 71.

21. Wise, P. Grow Your Own: The Potential Value and Impacts of Residential and Community Food Gardening; The Australia Institute: Canberra, Australia, 2014; p. 59. Available online: http://apo.org.au/node/39181 (accessed on 1 June 2016).

22. Conway, T. Home-based Edible Gardening: Urban Residents' Motivations and Barriers. Cities Environ. 2016, 9,3 .

23. Kortright, R.; Wakefield, S. Edible backyards: A qualitative study of household food growing and its contributions to food security. Agric. Hum. Values 2011, 28, 39-53. [CrossRef]

24. Taylor, J.; Lovell, S. Urban home food gardens in the Global North: Research traditions and future directions. Agric. Hum. Values 2013, 31, 285-305. [CrossRef]

25. Deppe, C. The Resilient Gardener: Food Production and Self-Reliance in Uncertain Times; Chelsea Green Publishing: White River Junction, VT, USA, 2010.

26. Pollard, G.; Ward, J.; Roetman, P. Typically Diverse: The Nature of Urban Agriculture in South Australia. Sustainability 2018, 10, 945. [CrossRef]

27. Cleveland, D.; Orum, T.; Ferguson, N. Economic value of home vegetable gardens in an urban desert environment. Hortic. Sci. 1985, 20, 694-696.

28. Codyre, M.; Fraser, E.; Landman, K. How does your garden grow? An empirical evaluation of the costs and potential of urban gardening. Urban For. Urban Green. 2014, 14, 72-79. [CrossRef]

29. Pollard, G.; Roetman, P.; Ward, J. The case for citizen science in urban agriculture research. Future Food J. Food Agric. Soc. 2017, 5, 9-20.

30. Stall, W.M. Economic value of a home vegetable garden in South Florida. Proc. Fla. State Hortic. Soc. 1979, 92, 213-214.

31. Utzinger, J.; Connolly, H. Economic value of a home vegetable garden. HortScience 1978, 13, 148-149.

32. Driver, B. Master List of Items for Recreation Experience Preference Scales and Domains; USDA Forest Service, Rocky Mountain Forest and Range Experiment Station: Fort Collins, CO, USA, 1983; Unpublished document.

33. Weber, D.; Anderson, D. Contact with nature: Recreation experience preferences in Australian parks. Ann. Leis. Res. 2010, 13, 46-69. [CrossRef]

34. Martin, K.; Rogers, B.; Cook, J.; Joseph, H. Social capital is associated with decreased risk of hunger. Soc. Sci. Med. 2004, 58, 2645-2654. [CrossRef] [PubMed]

35. Sampson, R.; Raudenbush, S.; Earls, F. Neighborhoods and violent crime: A multilevel study of collective efficacy. Science 1997, 277, 918-924. [CrossRef] [PubMed] 
36. Vitiello, D.; Nairn, M.; Grisso, J.; Swistak, N. Community Gardening in Camden, NJ Harvest Report: Summer 2009; Penn's Center for Public Health Initiatives: Philadelphia, PA, USA, 2010; Available online: http:/ / camdenchildrensgarden.org/Community\%20Gardening\%20Harvest\%20Report. pdf (accessed on 1 June 2016).

37. Zainuddin, Z.; Mercer, D. Domestic Residential Garden Food Production in Melbourne, Australia: A fine-grained analysis and pilot study. Aust. Geogr. 2014, 45, 465-484. [CrossRef]

38. Hawkins, D. Biomeasurement: A Student's Guide to Biostatistics, 3rd ed.; Oxford University Press: Oxford, UK, $2014 ;$ p. 333.

39. Kiesling, F.M.; Manning, C.M. How green is your thumb? Environmental gardening identity and ecological gardening practices. J. Environ. Psychol. 2010, 30, 315-327. [CrossRef]

40. Kingsley, J.; Townsend, M. 'Dig In' to Social Capital: Community Gardens as Mechanisms for Growing Urban Social Connectedness. Urban Policy Res. 2006, 24, 525-537. [CrossRef]

41. Twiss, J.; Dickinson, J.; Duma, S.; Kleinman, T.; Paulsen, H.; Rilveria, L. Community gardens: Lessons learned from California Healthy Cities and Communities. Am. J. Public Health 2003, 93, 1435-1438. [CrossRef] [PubMed]

42. Galhena, D.; Freed, R.; Maredia, K. Home gardens: A promising approach to enhance household food security and wellbeing. Agric. Food Secur. 2013, 2, 8. [CrossRef]

43. Click, M.; Ridberg, R. Saving food: Food preservation as alternative food activism. Environ. Commun. 2010, 4, 301-317. [CrossRef]

44. Butterfield, B. The Impact of Home and Community Gardening in America; National Gardening Association: South Burlington, VT, USA, 2009; p. 17. Available online: https:/ / community-wealth.org/content/impacthome-and-community-gardening-america (accessed on 1 June 2016).

45. Algert, S.J.; Baameur, A.; Diekmann, L.O.; Gray, L.; Ortiz, D. Vegetable Output, Cost Savings, and Nutritional Value of Low-Income Families' Home Gardens in San Jose, CA. J. Hunger Environ. Nutr. 2016, 11, 328-336. [CrossRef]

46. Conk, S. Quantifying Yields of Home and Community Gardens in Laramie, Wyoming; University of Wyoming: Laramie, WY, USA, 2015.

47. Pourias, J.; Duchemin, E.; Aubry, C. Products from urban collective gardens: Food for thought or for consumption? Insights from Paris and Montreal. J. Agric. Food Syst. Community Dev. 2015, 5, 1-25. [CrossRef]

48. Alaimo, K.; Packnett, E.; Miles, R.A.; Kruger, D.J. Fruit and vegetable intake among urban community gardeners. J. Nutr. Educ. Behav. 2008, 40, 94-101. [CrossRef] [PubMed]

49. Carney, P.; Hamada, J.; Rdesinski, R.; Sprager, L.; Nichols, K.; Liu, B.; Pelayo, J.; Sanchez, M.; Shannon, J. Impact of a community gardening project on vegetable intake, food security and family relationships: A community-based participatory research study. J. Community Health 2012, 37, 874-881. [CrossRef] [PubMed]

50. Walsh, M. Household Food Gardening: Its Contribution to Urban Resilience. Master's Thesis, University College Dublin, Dublin, Ireland, June 2015.

51. Watts, M. Public Understanding of Plant Biology: Voices from the Bottom of the Garden. Int. J. Sci. Educ. Part B 2015, 5, 1-18. [CrossRef]

52. Zahina-Ramos, J. Attitudes and Perspectives about Backyard Food Gardening: A Case Study in South Florida; Florida Atlantic University: Boca Raton, FL, USA, 2013.

(C) 2018 by the authors. Licensee MDPI, Basel, Switzerland. This article is an open access article distributed under the terms and conditions of the Creative Commons Attribution (CC BY) license (http://creativecommons.org/licenses/by/4.0/). 